\title{
Estrogen Differentially Affects Expression of Calcium Handling Genes in Female and Male Adult Cardiomyocytes
}

\author{
Xiaojing $\mathrm{Mu}^{\mathrm{a}}$ and Dr. Pamela Harvey ${ }^{\mathrm{a}, \mathrm{b}}$
}

Premenopausal women have a lower risk of developing heart disease compared with postmenopausal women and age-matched men. However, the debate about whether estrogen is cardioprotective is ongoing due to conflicting results from basic science and clinical trials as well as signaling pathways that make interpretation of effects difficult. Calcium handling in the contracting cells of the heart, the cardiomyocytes, is one of the most important pathways involved in heart function. We sought to determine if calcium-handling genes are regulated by estrogen in a sexually dimorphic manner to explain differences in heart health between men and women. Cardiomyocytes were isolated from the hearts of healthy male and female rats and were treated with different doses of estrogen (300pM, 10nM). Expression of a set of calcium handling genes was then measured to determine the effect of estrogen. Our results demonstrate that estrogen differentially regulates calcium-handling genes in female and male cells, an effect that is also dose-dependent. To our knowledge, this is the first study to examine expression of this comprehensive set of calciumhandling genes in response to estrogen and to consider its effects separately on cardiomyocytes isolated from males and females.

Keywords: Estrogen, ARVM, NRVM, calcium handling, genetic expression

\section{Introduction}

Worldwide, cardiovascular disease has become the leading cause of death for both women and men ${ }^{1}$. However, there are important differences in the incidence of heart disease between women and men $^{2}$. For example, mortality rates among premenopausal women with chronic heart failure are significantly lower than age-matched $\operatorname{men}^{2,3}$. Although younger women generally experience better heart health, the incidence of heart disease increases significantly in postmenopausal women ${ }^{4}$. Additionally, older women with some forms of heart disease have different symptoms and worse prognoses than $\mathrm{men}^{5}$. Therefore, younger women appear to be protected from heart disease, but when hormone levels dramatically drop at menopause, their cardiovascular outcomes decline. Therefore, we tested the hypothesis that estrogen contributes to normal cardiac function through regulation of genes that mediate contractility.

The effects of estrogen are mainly mediated by binding to estrogen receptors (ERs) $\alpha$ and $-\beta$ resulting in their translocation to the nucleus; however, there are non-receptormediated effects as well. Both ER $\alpha$ and ER $\beta$ mediate sexspecific cardioprotective effects of estrogen in the cardiovascular system. $\mathrm{ER} \alpha$ is required to protect the myocardium from acute ischemia-reperfusion injury in females and ER $\beta$ systemic knockout mice with myocardial infarction and pressure overload have increased cardiac pathology in females but not males ${ }^{6,7}$. Other studies have also demonstrated markers of heart failure and mortality increase in both male and female ER $\beta$ systemic knockout mice following myocardial infarction, suggesting that ER $\beta$ attenuates the development of chronic heart failure in this setting. ${ }^{8}$ To further define the role of ER $\beta$ in the heart and limit the complicated interpretation of a systemic knockout, we studied an ER $\beta$ cardiac-specific knockout mice in which only male mice show cardiac hypertrophy (data not shown). Other unpublished studies in our lab demonstrate functional cardiac pathology in ER $\alpha$ cardiac-specific knockout female but not male mice. The mechanism by which ERs and estrogen signaling affect cardiac function remains to be fully understood.

The effects of estrogen are complex because of the numerous signaling pathways it modulates. Binding of estrogen to ERs leads to receptor dimerization and recruitment of coregulators. The estrogen-ER complex is then translocated to the estrogen response elements (ERE) on DNA to alter gene expressions. However, some genes regulated by ER do not have an ERE. In this situation, transcription factors are required to activate and inactivate gene expression, such as AP1, which controls numerous cellular process including differentiation, proliferation and apoptosis, and Sp1, which is involved in early development of organism. Even without estrogen, ER can influence EREs via phosphorylation by growth factor and other plasma membrane estrogen receptors to modulate gene transcription ${ }^{9}$.

Research on breast cancer cells indicates that estrogen regulates many cellular processes, including cell division, actin dynamics and expression of ion channels ${ }^{9}$. Although not directly implicated in this research, we hypothesized that regulation of ion channels involved in calcium handling in the cardiac myocytes may also be regulated by estrogen. This is of particular interest because cyclical maintenance of appropriate intracellular calcium concentrations is required for normal cardiac muscle contraction and relaxation.

The cardiac myocyte is a specialized muscle cell composed of bundles of myofibrils. The basic contractile units of the myocytes, sarcomeres, are primarily comprised of myosin and actin, which interact both chemically and physically to change cell length and thus cause contraction. When the cell is depolarized by inward calcium current, other plasma membrane voltage-gated calcium channels open and intracellular stores of calcium are released from the sarcoplasmic reticulum (SR). Calcium binds to the myofilament protein troponin, which then switches on the 
interaction between actin and myosin, causing contraction ${ }^{10}$. To facilitate this process, intracellular calcium concentrations must be precisely regulated. Therefore, the genes involved in calcium handling have key roles in appropriate heart function.

To address the mechanism by which estrogen modulates cardiac function, expression of components of the excitationcontraction coupling process were measured using quantitative PCR. Several channels are involved in maintaining intercellular calcium concentrations in the physiological range (Figure 1$)^{11}$. The sarcolemmal L-type voltage dependent calcium channels Cav1.1, also known as dihydropyridine receptor (DHPR) or CACNA1S, Cav1.2 and sodium-calcium exchanger (NCX) are channels that allow extracellular calcium to enter the cardiomyocyte. The ryanodine receptor 2 (RyR2) localized in the SR membrane also plays an important role in increasing calcium concentrations upon excitation of the cell. To reduce calcium concentrations in the cardiomyocyte after contraction, the plasma membrane calcium-ATPase (PMCA) transports calcium out of the cells in exchange for protons. Among those genes, none has the ERE sequence (5' GGTCAnnnTGACC 3') in mouse or human ${ }^{12}$; these genes may be regulated indirectly by estrogen signaling.

To determine whether estrogen regulates expression of these important channels, cardiomyocytes were isolated from adult and neonatal rat hearts and treated with vehicle or different concentrations of estrogen (10nM or $300 \mathrm{pM})$. Quantitative PCR was used to detect the expression levels of these calcium handling genes to determine the effects of estrogen. Our data show that estrogen regulates expression of these genes differently in female and male adult rat ventricular myocytes (ARVMs) in a highly dose-dependent manner. Importantly, our data also demonstrate that the commonly used neonatal cardiac cell model may not be appropriate for studies of sex hormones in the heart, especially those that may be sexually dimorphic.

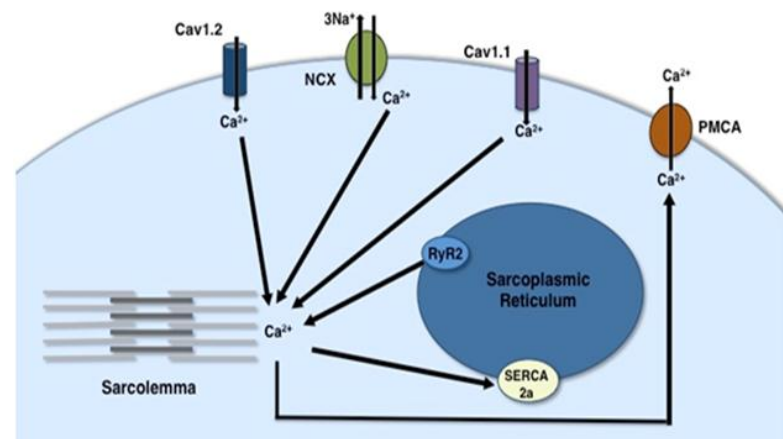

Figure 1: The relationship between key components in the excitation-contraction coupling process. Calcium concentrations in the cardiomyocyte are regulated by several ion channels in the cardiomyocyte. Cav1.1 and Cav1.2, voltage-gated L-type calcium channels, as well as NCX move calcium into the cell from the extracellular space. Calcium also enters the cytoplasm from the sarcoplasmic reticulum. Following contraction, calcium is sequestered into the SR by SERCA2 $a$ and is returned to the extracellular space via PMCA.

\section{Experimental Procedures}

Adult Rat Ventricular Myocyte Isolation

All animal procedures were performed with the approval by the University of Colorado at Boulder Institutional Animal Care and Use Committee. ARVMs were isolated as previously described with minor modification as follows ${ }^{13}, 14$. Briefly, male or female 6-8-week-old rats that were approximately $350 \mathrm{~g}$ were injected with $250 \mathrm{U}$ heparin (Sagent, Schaumberg, IL). After ten minutes, the rat was injected intraperitoneally with $35 \mathrm{mg} / \mathrm{kg}$ sodium pentobarbital solution (Vortech, Dearborn, MI). When the rat was completely and deeply anesthetized, as determined by firm toe pinch, the thoracic cavity was exposed by cutting the peritoneal muscle and ribs on both sides. The heart was excised including about $5 \mathrm{~mm}$ of aorta required for cannulation. The heart was then transferred into $0.9 \% \mathrm{NaCl}$ solution to manually pump the blood from the heart. Forceps were used to cannulate the aorta while immersed in $0.9 \% \mathrm{NaCl}$ solution to prevent the introduction of bubbles and the aorta was secured using silk suture. Isotonic buffer heated to $37^{\circ} \mathrm{C}$ was used to perfuse the heart for five minutes and $1.455 \mathrm{mg} / \mathrm{ml}$ collagenase type II solution was then used to digest the heart for 20-30 minutes. The heart was removed, cut into small pieces in the collagenase solution, incubated for two minutes, and dissociated using glass Pasteur pipets bent at $90^{\circ}$. Cells were transferred to a $15 \mathrm{~mL}$ tube and centrifuged at $100 \mathrm{rpm}$ for 3 minutes to pellet the cells. Supernatant containing dead cells and non-myocytes was discarded. 10ml Media 199 (Invitrogen, Carlsbad, CA) was added; cells were resuspended and centrifuged as above. Cell concentration was determined and the pellet was resuspended at $10,000-20,000$ cells $/ \mathrm{mL}$ in Springhorn Media (Media 199 with $0.2 \%$ bovine serum albumin, $\quad 1.6 \mathrm{mmol} / \mathrm{L}$ L-carnitine, $4.4 \mathrm{mmol} / \mathrm{L}$ creatine monohydrate, $5 \mathrm{mmol} / \mathrm{L}$ L-taurine, $4 \mu \mathrm{mol} / \mathrm{L}$ L-glutamine, $5 \mu \mathrm{mol} / \mathrm{L}$ sodium pyruvate, $10 \mathrm{mmol} / \mathrm{L}$ 2,3-butanedione monoxime, $17.4 \mathrm{nmol} / \mathrm{L}$ insulin) and plated on $60 \mathrm{~mm}$ plastic cell culture plates coated with $10 \mu \mathrm{g} / \mathrm{mL}$ laminin (Invitrogen, Carlsbad, CA). Plates were incubated at $37^{\circ} \mathrm{C}$ with $5 \% \mathrm{CO}_{2}$ for 3-5 hours. Cells were then washed with Springhorn media to remove dead cells and treated with vehicle (ethanol), $300 \mathrm{pM}$ estradiol (E2), or $10 \mathrm{nM} \mathrm{E} 2$ for $36 \mathrm{~h}$. The dose of $300 \mathrm{pM}$ was chosen because it represents a physiologic level of estrogen exposure. Adult female rats have serum estrogen between $20 \mathrm{pg} / \mathrm{mL}$ and $40 \mathrm{pg} / \mathrm{mL}(73.5 \mathrm{pM}$ to $147 \mathrm{pM})$ during cycle. During pregnancy, serum estrogen peaks at $140 \mathrm{pg} / \mathrm{mL}$ $(514.5 \mathrm{pM})^{15}$. The $10 \mathrm{nM}$ dose was chosen because this higher dose is commonly used in other studies that examine the effects of estrogen in cardiomyocytes, regardless of sex ${ }^{16,17}$. Two to three plates were used per treatment and three separate isolations were performed per sex.

\section{Neonatal Rat Ventricular Myocyte (NRVM) Isolation}

NRVMs were isolated as previously described with modification of cell culture conditions as follows ${ }^{19}$. Briefly, cells were isolated, plated at 100,000 cells $/ \mathrm{mL}$ on $60 \mathrm{~mm}$ plastic cell culture plates and incubated for 24 hours at $1 \%$ $\mathrm{CO}_{2}$ in growth media containing calf serum. Cells were then washed and transferred to serum-free media. Vehicle (ethanol), 300pM E2, or 10nM E2 were applied to the media and plates were incubated for 48 hours. Cells isolated in each preparation are a pooled population of cells isolated from 50- 
75 neonatal rats, and pooled cells are distributed among the members of the laboratory for use. 300,000 cells were plates per $60 \mathrm{~mm}$ plate thus approximately $14-16$ neonatal per experiment. Three plates were used per treatment and two isolations were performed.

\section{RNA Isolation}

$300 \mu 1$ TRI Reagent (Molecular Research Center, Cincinnati, $\mathrm{OH}$ ) was added to two to three plates per treatment. Cells were scraped into a single $1.5 \mathrm{~mL}$ tubes so each tube contained lysates from the same treatment. RNA was then isolated according to manufacturer protocol.

\section{cDNA synthesis}

RNA concentration was determined using a Nanodrop (Thermo Scientific, Waltham, MA). The appropriate volume of RNA was used to obtain 500ng, $1 \mu \mathrm{g}$ or $2 \mu \mathrm{g}$ in a $20 \mu \mathrm{L}$ reaction. cDNA was synthesized using, Superscript II $^{\mathrm{TM}}$ reverse transcriptase (Invitrogen, Carlsbad, CA) and random hexamer primers according to manufacturer protocol.

The RNA concentrations obtained from ARVMs were in the range of $70 \mathrm{ng} / \mu \mathrm{l}$ to $160 \mathrm{ng} / \mu \mathrm{l}$ and $\mathrm{A} 260 / \mathrm{A} 280$ ratios indicating the degree of protein contamination were in an acceptable range (above 1.75). RNA concentrations from NRVMs were between $200 \mathrm{ng} / \mu \mathrm{l}$ and $678 \mathrm{ng} / \mu \mathrm{l}$. A260/A280 ratios were above 1.9. Primer-BLAST (National Library of Medicine) was used to verify that the designed primers amplified the intended product in silico. A single melt curve of each quantitative PCR product with a peak at the expected melt temperature suggested that the reaction amplified a single product. The R-squared values for standard curves using each primer set were above 0.99, indicating the technical replicates were reliable. The slope of the standard curves for each primer set produced using 10-fold dilutions fro ${ }^{20} \mathrm{~m} 40 \mathrm{ng}$ to $0.004 \mathrm{ng}$ per reaction and a non-template control were all less than -3.0 , indicating that the products were amplified efficiently ( -3.3 is approximately equal to $100 \%$ efficiency).

\section{Primer Design}

Ensembl Genome Browser was used to identify the cDNA sequence of each gene and select sequence that included least two exons ${ }^{21}$. Primer3 was then used to select different sets of primers that spanned an intron to eliminate possible amplification of genomic DNA ${ }^{22}$. The primer length was set as $18-22 \mathrm{bp}$, primer melting temperature as $52-58^{\circ} \mathrm{C}$, and GC content as $40-60 \%$. Primer sequences are shown in Table 1 .

\section{Quantitative PCR}

Expression of each gene was quantified by measuring SYBR $^{\circledR}$ Green (Invitrogen, Carlsbad, CA) incorporated into PCR products using an Applied Biosystems 7500 Real-Time PCR System (Foster City, CA). 4ng of cDNA were used per well with $6 \mu \mathrm{L}$ of $\mathrm{SYBR}^{\circledR}$ Green master mix and appropriate primer pairs. Each sample was loaded in triplicate and standard curves were produced for each gene examined. Expression of genes of interest was normalized to expression of $18 \mathrm{~S}$ ribosomal RNA for each sample and changes in expression were determined by comparing to untreaed cells. $18 \mathrm{~S}$ was chosen as a reference gene because it varied by less than $2.3 \%$ and $4.8 \%$ in male or female samples, respectively. Data were reported relative to vehicle-treated cells for each gene of interest. The thermocycler program used is shown in Figure 2.

\section{Data presentation}

All data are shown in bar graphs produced using Prism 4 for Macintosh as mean \pm standard error from the mean (S.E.M.), calculated from three biological replicates per experiment. Expression from individual biological replicates was calculated using the algorithm in the Bio-Rad CFX Manager software, which normalizes expression according to the primer efficiency determined in the standard curve for the primer set. Statistically significant differences between groups were determined using unpaired Student's t-test; significance was defined as $\mathrm{p}<0.5$.

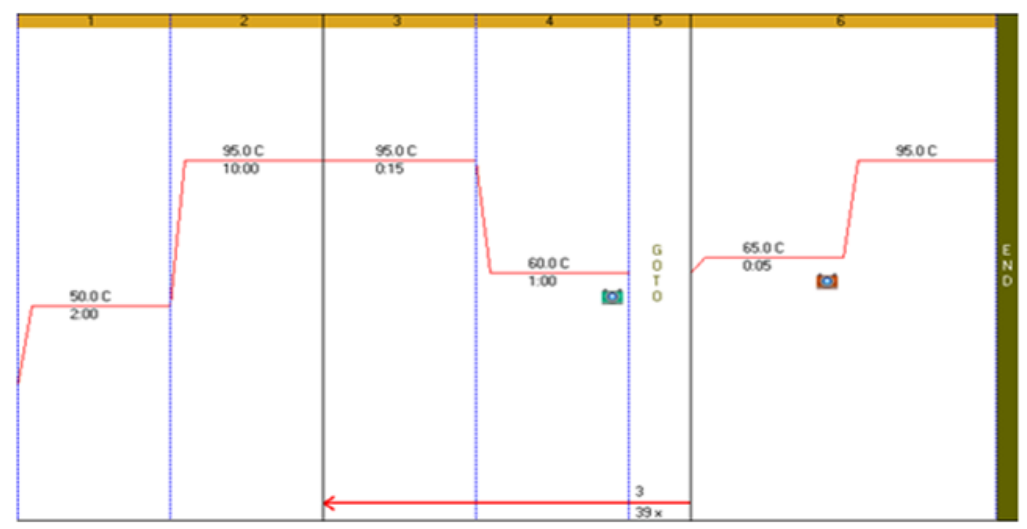

Figure 2: Quantitative PCR program.

Table 1: DNA sequences of oligonucleotide primers for Cav1.1, Cav1.2, NCX, PMCA and RyR2. Primers for 18S ribosomal RNA were used as a reference.

\begin{tabular}{|ccccc|}
\hline Gene & Forward Primer & Reverse Primer & Size (bp) \\
\hline Cav1.1 & 5' GCCTACGGACTTCTCTTCCA 3' & 5' GCTCCTTTCCCTCCTAGAGC 3' & 149 \\
\hline Cav1.2 & 5' GCCAGAGGATGACAACAACA 3' & 5' GATGGAATAGGAAGCCGTAGG 3' & 119 \\
\hline NCX & 5' CGTCTGGTGGAGATGAGTGA 3' & 5' TGGTGTGTTCGCCTAGAATG 3' & 139 \\
\hline PMCA & 5' TGGCAGCATGTATATCTTTCGT 3' & 5' GGCTACCAAGATAAGCAGAATTACA 3' & 101 \\
\hline RyR2 & 5' ACGGATGATGAAGTGGTCCT 3', & 5' GATCAGGGGGTACATTCTGC 3' & 139 \\
\hline 18S rRNA & 5' GCCGCTAGAGGTGAAATTCTTG 3' & 5' CTTTCGCTCTGGTCCGTCTT 3' & 66 \\
\hline
\end{tabular}


PCR products were amplified by repeated denaturation $\left(95^{\circ} \mathrm{C}\right)$ and elongation $\left(60^{\circ} \mathrm{C}\right)$. The amount of fluorescence, an indication of the amount of PCR product, was measured after each elongation step (blue camera icon). At the end of the program, a melt curve was obtained by increasing the temperature by $2^{\circ} \mathrm{C}$ for 5 seconds and measuring the fluorescence after each increase (orange camera icon). The peak temperature was determined to be the melt temperature where $50 \%$ of the product was denatured. Image obtained from Bio-Rad CFX Manager software.

\section{Results}

ARVM isolation yielded healthy rod-shaped cardiomyocytes

Healthy rod-shaped cardiomyocytes were identified visually using a light microscope and a $20 \mathrm{X}$ objective. The percentage of myocytes increased significantly after washing, with the majority of cells appearing to be rod-shaped cardiomyocytes after the wash. All cardiomyocytes were adhered tightly to the surface of the plates. Some of them were spontaneously contracting, indicating that they were in healthy condition.

Quantitative PCR revealed different patterns of expression of calcium handling genes in female and male ARVMs.

Female and male cardiomyocytes treated with different doses of estrogen showed different genes expression patterns. Female ARVMs treated with 300pM E2 had down-regulated genes compared to vehicle-treated control as follow: Cav1.1 (0.956 \pm 0.058), Cav1.2 (0.601 \pm 0.060$)$, NCX (0.542 \pm $0.130)$, PMCA (0.802 \pm 0.003$), \operatorname{RyR} 2(0.841 \pm 0.037)$. Male ARVMs treated with $300 \mathrm{pM}$ E2 showed similar downregulated gene expression, except for $\mathrm{NCX}$, which was undetectable in these experiments [Cav1.1 (0.978 \pm 0.048$)$, Cav1.2 (0.604 \pm 0.030$)$, PMCA (0.539 \pm 0.03$)$, RyR2 (0.703 $\pm 0.040)$ ] (Figure 3A). Expression of only one gene (PMCA) was statistically different between male and female cells treated with 300pM E2. NCX expression is not reported for male ARVMs because we were unable to obtain reproducible amplification data. Amplification was only observed when 40ng of cDNA were used but the technical replicates were inconsistent. We conclude that NCX expression was insufficient to be detected using our methods.

When cells were exposed to a higher dose of estrogen (10nM), male and female ARVMs had dramatically different gene expression changes. This supraphysiologic dose is commonly used to model cellular responses to $\mathrm{E} 2^{6,}{ }^{16}$. Calcium handling genes were still down-regulated in female ARVMs [Cav1.1 (0.619 \pm 0.101$)$, Cav1.2 (0.580 \pm 0.070$)$, NCX $(0.574 \pm 0.018)$, PMCA $(0.613 \pm 0.038)$, RyR2 (0.803 \pm 0.074)]. Cav1.1, PMCA, and RyR2 had a dose-dependent decrease in expression compared to female ARVMs treated with 300pM E2. However, the male ARVMs exhibited the opposite response with statistically significant ( $p<0.01)$ upregulation of all calcium handling genes except for RyR, which was increased but was not determined to be significantly different from expression in female cells (Figure 3B). Male ARVMs treated with 10nM E2 showed similar down-regulated gene expression, except for NCX, which was undetectable in these experiments [Cav1.1 (1.33 \pm 0.102$)$,
Cav1.2 (0.953 \pm 0..020), PMCA (1.159 \pm 0.101$),$ RyR2 $(0.985 \pm 0.030)]$ (Figure 3A).

A.

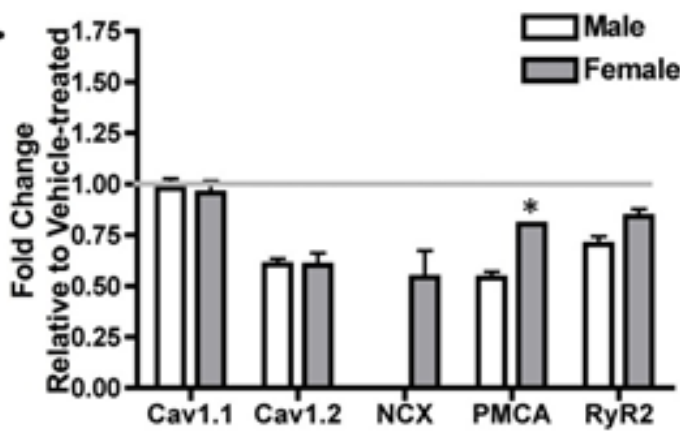

B.
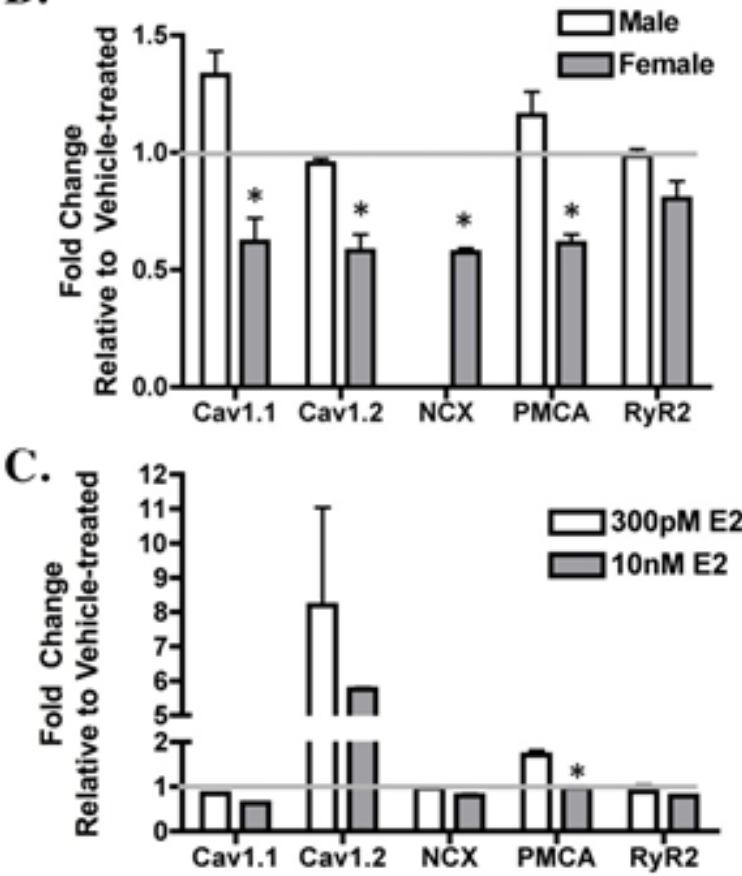

Figure 3: (A) Expression of calcium handling genes in male and female ARVMs treated with 300pM E2. Open bars represent male ARVMs and gray bars represent female ARVMs. $* \mathrm{p}<0.01$ (B) Expression of calcium handling genes in male and female ARVMs treated with 10nM E2. Open bars represent male ARVMs and gray bars represent female ARVMs. $*$ p $<0.01$ (C) NRVMs treated with $300 \mathrm{pM}$ E2 (open bars) and 10nM E2 (gray bars). Gray line in each graph indicates no change in expression relative to vehicletreated. $* \mathrm{p}<0.01$ Error bars indicate S.E.M.

Neonatal rat ventricular myocytes (NRVMs) were also isolated and treated to determine whether calcium handling gene expression is also modulated by estrogen in these cells. NRVMs are a commonly used cell model to study cardiac responses to many hormone, drug and pathologic conditions ${ }^{23-}$ 25. Although convenient because of ease of isolation and longer-term maintenance in culture ${ }^{19}$, these cells represent a mix of cells from male and female hearts and may not be as 
responsive as adult cells to sex hormones. Significant differences were found for NRVMs treated with $300 \mathrm{pM} \mathrm{E} 2$ and $10 \mathrm{nM}$ E2 compared to ARVMs isolated from rats of either sex (Figure 3C). A dose-dependent decrease in expression of all genes tested was observed in NRVMs treated with $10 \mathrm{nM}$ E2 compared to 300pM E2 (Cav1.1 26.2\%, Cav1.2 -\%, NCX -28.7\%, PMCA -62.5\%, RyR2 $21.3 \%$ ). With the exception of Cav1.2, all genes were downregulated with both doses of E2; only the reduction of RyR2 was significant. The response of NRVMs did not accurately mimic the response of male or female ARVMs.

\section{Discussion}

Estrogen regulates calcium handling genes.

Evaluation of ARVMs showed that calcium handling gene expression is modulated by estrogen. With both physiologic (300pM) and supraphysiologic (10nM) estrogen (see methods), expression of genes responsible for encoding channels that transport calcium in male and female adult cardiomyocytes is altered. NCX was below detection in male ARVMs, which was probably because the expression level was too low in male cardiomyocytes. Other groups have demonstrated that NCX is expressed in female and male rat heart ventricular tissues by using western blots. They also proved that NCX and RyR had higher mRNA levels in female rat heart ventricular tissue compared to males, which is consistent with our studies ${ }^{26}$. In addition, NRVMs treated with estrogen also showed different calcium handling gene expression compared to vehicle-treated. These data demonstrate that estrogen regulates expression of calcium handling genes in cardiomyocytes and the effect is dosedependent. To our knowledge, these are the first studies to examine this combined set of calcium handling genes to determine expression changes with exposure of estrogen in both female and male cardiomyoctyes. Importantly, we also show different responses between male and female adult cell and between adult and neonatal cells.

Physiologic and supraphysiologic doses of estrogen regulate calcium handling genes in males and females differently.

Other studies have already shown that ER $\alpha$ knockout mice had increased L-type calcium channels ${ }^{27}$. In our studies, calcium handling genes were down-regulated fin both female and male ARVMs treated with 300pM E2, in agreement with this study. With this physiological dose of estrogen, female and male showed similar responses. However, when the estrogen dose was increased to $10 \mathrm{nM}$, a dose that is normally used for estrogen-related research, expression of calcium handling genes still decreased for female cardiomyocytes in a dose-dependent manner, but increased dramatically for male cardiomyocytes. These data therefore suggest that male cardiac myocytes may be more sensitive to this supraphysiologic estrogen dose. Our preliminary data (not shown) suggest that there are significant differences in ER expression in male and female ARVMs, which could account for this increased sensitivity. Hence, researchers should be aware of this effect when studies are performed in adult cardiomyocytes, especially in males because higher doses of estrogen may causes abnormal regulation of calcium handling genes resulting in incorrect interpretation of results.
NRVMs may not be appropriate for studying sex-specific responses to estrogen.

NRVMs are a common model for studying sex hormones because of the ease of preparation and health in culture ${ }^{19}$. However, our data from NRVMs suggest that it might not be a reliable model to study the effect of sex hormones on calcium handling genes. Because male and female neonatal rats are not easily sexed visually, ventricles from multiple hearts are typically pooled, so NRVMs preparations represent a mix cells from both males and females ${ }^{28}$. The male-specific SYR gene can be measured using PCR to distinguish between male and female neonates ${ }^{29}$, however this technique is rarely used in studies using cultured NRVMs, even in studies involving sex hormones ${ }^{23}, 30,31$. Additionally, NRVMs are isolated from a neonatal environment rather than an adult one, so the effect of sex hormones may be different. In our study, data from NRVMs did not reflect the gene expression portfolio of either male or female ARVMs. Therefore, researchers should be aware of this issue in NRVMs if the effects of sex hormones are to be studied in isolated cardiomyocytes.

Estrogen supplementation might be harmful to cardiac health in males.

The debate of whether estrogen supplementation should be provided to males for cardiac protection has been active for many years. Despite the suggestion that estrogen may be protective in females, these studies have been recently questioned and many studies have shown that estrogen might be harmful to males, especially in the context of heart disease $^{32,33}$. For example, estrogen supplementation in men can cause negative cardiac effects, leading to increased death rates after myocardial infarction ${ }^{34,35}$. In light of our data on physiologic doses of estrogen in male and female ARVMs, we hypothesized that exposure to higher doses of estrogen would down-regulate calcium handling genes. However, male but not female ARVMs treated with 10nM estrogen had the opposite gene expression pattern. Dramatic increases in expression of calcium handling genes that move calcium into the sarcoplasm could be responsible for pathology. Calcium overload in cardiomyocytes is believed to cause pathology in cardiac myocytes, indicating that the dramatic up-regulation of calcium handling genes in male ARVMs treated with high dose of estrogen might be harmful to the cardiac health of males. Interestingly, however, estrogen has been shown to have cardioprotective effects on female cardiac myocytes because of a decrease of intercellular calcium but not on male cardiac myocytes ${ }^{36}$. Our studies agree with this; isolated female cardiomyocytes to estrogen down-regulated calcium handling genes. Thus, the dose of estrogen can have dramatic effects on the health of the heart and males and females should be considered differently in this determination.

\section{Conclusions}

Much remains to be understood about the effects of estrogen in males and females in terms of cardiac health. The data presented here comprehensively examine the effects of estrogen on calcium handling in isolated adult cardiac myocytes, an important model that excludes effects of other cells in the heart or of pathology in the cardiovascular system that can indirectly affect cardiac function and allows 
consideration of male and female cells separately. We show that estrogen affects male and female ARVMs differently and raise important questions about its effects on calcium handling in the heart. Additionally, our experiments make a direct comparison between adult and neonatal cells and suggest that ARVMs are a superior model for the study of sex hormones in cardiomyocytes.

\section{Limitations and future directions}

The effect of estrogen is complicated because of involvement of numerous signaling pathways and genes. Even when considering only calcium handling pathways, it proves to be a complex story. Estrogen can protect the heart cells by reducing the intercellular calcium in females, but it also can cause pathology by increasing calcium. The key point here is female and male cells have different responses to varying doses of estrogen. Male cardiomyocytes appear to be more sensitive to estrogen dose, which would make identification of the correct dose for men difficult. This issue may also exist for choosing the correct dose for post-menopausal women. From our studies, it is not appropriate to make the conclusion that high dose estrogen caused pathological changes on male cardiomyocytes however, our data suggest that more studies are required to examine appropriate doses in males and females if estrogen supplementation is to be considered to protect the heart.

While many of the ARVMs were still contracting when they were first isolated, this spontaneous activity did not continue in cell culture. This suggests that many of the normal calcium handling processes have been made inactive in these cells. Despite this, our studies still suggested a dramatic effect on calcium handling genes regulation by estrogen. In the future, the contractile function of male and female ARVMs treated with different dose estrogen should be measured to make interpretation of these data more clear.

\section{Acknowledgements}

I would like to thank my advisor Leslie Leinwand for providing this great research opportunity. In addition, I gratefully acknowledge Ann Robinson for isolating NRVMs used in these studies. This manuscript was prepared with support from the American Heart Association (Postdoctoral Fellowship 11POST7780011 to P.A.H.).

\section{References}

1. Liu PY, Death AK, Handelsman DJ: Androgens and cardiovascular disease, Endocr Rev 2003, 24:313-340

2. Babiker FA, De Windt LJ, van Eickels M, Grohe C, Meyer R, Doevendans PA: Estrogenic hormone action in the heart: regulatory network and function, Cardiovasc Res 2002, 53:709-719

3. Jneid H, Thacker HL: Coronary artery disease in women: different, often undertreated, Cleve Clin J Med 2001, 68:441-448

4. Colditz GA, Willett WC, Stampfer MJ, Rosner B, Speizer FE, Hennekens CH: Menopause and the risk of coronary heart disease in women, N Engl J Med 1987, 316:1105-1110

5. Murabito JM, Evans JC, Larson MG, Levy D: Prognosis after the onset of coronary heart disease. An investigation of differences in outcome between the sexes according to initial coronary disease presentation, Circulation 1993, 88:2548-2555

6. Wang M, Crisostomo P, Wairiuko GM, Meldrum DR: Estrogen receptor-alpha mediates acute myocardial protection in females, Am J Physiol Heart Circ Physiol 2006, 290:H2204-2209

7. Skavdahl M, Steenbergen C, Clark J, Myers P, Demianenko T, Mao L, Rockman HA, Korach KS, Murphy E: Estrogen receptor-beta mediates male-female differences in the development of pressure overload hypertrophy, Am J Physiol Heart Circ Physiol 2005, 288:H469-476

8. Pelzer T, Loza PA, Hu K, Bayer B, Dienesch C, Calvillo L, Couse JF, Korach KS, Neyses L, Ertl G: Increased mortality and aggravation of heart failure in estrogen receptor-beta knockout mice after myocardial infarction, Circulation 2005, 111:1492-1498

9. Murphy E: Estrogen signaling and cardiovascular disease, Circ Res 2011, 109:687-696

10. Bers DM: Cardiac excitation-contraction coupling, Nature 2002, 415:198-205

11. Liao R, Helm PA, Hajjar RJ, Saha C, Gwathmey JK: $[\mathrm{Ca} 2+] \mathrm{i}$ in human heart failure: a review and discussion of current areas of controversy, Yale J Biol Med 1994, $67: 247-264$

12. Bourdeau V, Deschenes J, Metivier R, Nagai Y, Nguyen D, Bretschneider N, Gannon F, White JH, Mader S: Genome-wide identification of high-affinity estrogen response elements in human and mouse, Mol Endocrinol 2004, 18:1411-1427

13. Eid H, Larson DM, Springhorn JP, Attawia MA, Nayak RC, Smith TW, Kelly RA: Role of epicardial mesothelial cells in the modification of phenotype and function of adult rat ventricular myocytes in primary coculture, Circ Res 1992, 71:40-50

14. Cheung JY, Thompson IG, Bonventre JV: Effects of extracellular calcium removal and anoxia on isolated rat myocytes, Am J Physiol 1982, 243:C184-190

15. Shors TJ, Pickett J, Wood G, Paczynski M: Acute stress persistently enhances estrogen levels in the female rat, Stress 1999, 3:163-171

16. Mitra P, Pereira LA, Drabsch Y, Ramsay RG, Gonda TJ: Estrogen receptor-alpha recruits $\mathrm{P}-\mathrm{TEFb}$ to overcome transcriptional pausing in intron 1 of the MYB gene, Nucleic Acids Res 2012,

17. Wang J, Stern PH: Sex-specific effects of estrogen and androgen on gene expression in human monocytederived osteoclasts, J Cell Biochem 2011, 112:37143721

18. Faul F, Erdfelder E, Lang AG, Buchner A: G*Power 3: a flexible statistical power analysis program for the social, behavioral, and biomedical sciences, Behav Res Methods 2007, 39:175-191

19. Maass AH, Buvoli M: Cardiomyocyte preparation, culture, and gene transfer, Methods Mol Biol 2007, 366:321-330

20. Garcia AG, Wilson RM, Heo J, Murthy NR, Baid S, Ouchi N, Sam F: Interferon-gamma Ablation Exacerbates Myocardial Hypertrophy in Diastolic Heart Failure, Am J Physiol Heart Circ Physiol 2012, 
21. Flicek P, Amode MR, Barrell D, Beal K, Brent S, Chen Y, Clapham P, Coates G, Fairley S, Fitzgerald S, Gordon L, Hendrix M, Hourlier T, Johnson N, Kahari A, Keefe D, Keenan S, Kinsella R, Kokocinski F, Kulesha E, Larsson P, Longden I, McLaren W, Overduin B, Pritchard B, Riat HS, Rios D, Ritchie GR, Ruffier M, Schuster M, Sobral D, Spudich G, Tang YA, Trevanion S, Vandrovcova J, Vilella AJ, White S, Wilder SP, Zadissa A, Zamora J, Aken BL, Birney E, Cunningham F, Dunham I, Durbin R, Fernandez-Suarez XM, Herrero J, Hubbard TJ, Parker A, Proctor G, Vogel J, Searle SM: Ensembl, Nucleic Acids Res 2011, 39:D800-806

22. Rozen S, Skaletsky H: Primer3 on the WWW for general users and for biologist programmers, Methods Mol Biol 2000, 132:365-386

23. Koshman YE, Piano MR, Russell B, Schwertz DW: Signaling responses after exposure to 5 alphadihydrotestosterone or 17 beta-estradiol in norepinephrine-induced hypertrophy of neonatal rat ventricular myocytes, J Appl Physiol 2009, 108:686-696

24. Berdichevski A, Meiry G, Milman F, Reiter I, Sedan O, Eliyahu S, Duffy HS, Youdim MB, Binah O: TVP1022 protects neonatal rat ventricular myocytes against doxorubicin-induced functional derangements, $\mathbf{J}$ Pharmacol Exp Ther 2010, 332:413-420

25. Yaniv G, Shilkrut M, Lotan R, Berke G, Larisch S, Binah O: Hypoxia predisposes neonatal rat ventricular myocytes to apoptosis induced by activation of the Fas (CD95/Apo-1) receptor: Fas activation and apoptosis in hypoxic myocytes, Cardiovasc Res 2002, 54:611-623

26. Chu SH, Sutherland K, Beck J, Kowalski J, Goldspink P, Schwertz D: Sex differences in expression of calciumhandling proteins and beta-adrenergic receptors in rat heart ventricle, Life Sci 2005, 76:2735-2749

27. Collins P, Rosano GM, Jiang C, Lindsay D, Sarrel PM, Poole-Wilson PA: Cardiovascular protection by oestrogen--a calcium antagonist effect?, Lancet 1993, 341:1264-1265

28. Koshman YE, Piano MR, Russell B, Schwertz DW: Signaling responses after exposure to 5 alpha- dihydrotestosterone or 17 beta-estradiol in norepinephrine-induced hypertrophy of neonatal rat ventricular myocytes, J Appl Physiol 2010, 108:686-696

29. Dai W, Hale SL, Kloner RA: Implantation of immature neonatal cardiac cells into the wall of the aorta in rats: a novel model for studying morphological and functional development of heart cells in an extracardiac environment, Circulation 2004, 110:324-329

30. Babiker FA, De Windt LJ, van Eickels M, Thijssen V, Bronsaer RJ, Grohe C, van Bilsen M, Doevendans PA: 17beta-estradiol antagonizes cardiomyocyte hypertrophy by autocrine/paracrine stimulation of a guanylyl cyclase A receptor-cyclic guanosine monophosphate-dependent protein kinase pathway, Circulation 2004, 109:269-276

31. Eble DM, Strait JB, Govindarajan G, Lou J, Byron KL, Samarel AM: Endothelin-induced cardiac myocyte hypertrophy: role for focal adhesion kinase, Am J Physiol Heart Circ Physiol 2000, 278:H1695-1707

32. Jankowska EA, Rozentryt P, Ponikowska B, Hartmann O, Kustrzycka-Kratochwil D, Reczuch K, Nowak J, Borodulin-Nadzieja L, Polonski L, Banasiak W, PooleWilson PA, Anker SD, Ponikowski P: Circulating estradiol and mortality in men with systolic chronic heart failure, JAMA 2009, 301:1892-1901

33. Haines C, Harvey P, Leinwand L: Estrogenic compounds are not always cardioprotective and can be lethal in males with genetic heart disease, Endocrinology 2012,

34. The Coronary Drug Project. Findings leading to discontinuation of the 2.5-mg day estrogen group. The coronary Drug Project Research Group, JAMA 1973, 226:652-657

35. Asscheman H, Gooren LJ, Eklund PL: Mortality and morbidity in transsexual patients with cross-gender hormone treatment, Metabolism 1989, 38:869-873

36. Jovanovic S, Jovanovic A, Shen WK, Terzic A: Low concentrations of 17beta-estradiol protect single cardiac cells against metabolic stress-induced Ca2+ loading, J Am Coll Cardiol 2000, 36:948-952 